\title{
New Insights into Applied Linguistics: Rethinking the Teaching of Tenses
}

\author{
Drissia Chouit* \\ Laboratory of Research on Communication, Interculturality, Gender, Art, Language and Society \\ (LaRCIGALS), Moulay Ismail University of Meknes, Morocco
}

*Corresponding author:

E-mail: d.chouit@umi.ac.ma

\begin{abstract}
This feature article presents a new approach to the teaching of grammar in universities: A Meta-operational Grammar of English. Tackling one of the most important chapters of English grammar, the teaching of tenses, it aims to show (1) the importance of teaching grammar in context; (2) the importance of investing linguistic research in this pedagogical process; and most importantly, (3) the prerogative of understanding how a language works to master it. In other words, when students know how language works, they learn it easily and effectively, and they master the use of grammatical forms in context. It is the teaching pedagogy that is at stake here: a pedagogy that addresses students' intelligence and cognitive capacities to motivate them and help them become autonomous learners and skilled communicators.
\end{abstract}

Keywords: Meta-operational grammar, applied linguistics, tenses, abstract processing of utterances, communication strategies, grammar in context

\section{Introduction}

This research article tackles one of the most difficult chapters of English grammar, the teaching of tenses. It brings new insights to the field, targeting the capacity of students to understand, analyze and produce these grammatical forms in context to serve different communication goals. It also shows limitations of descriptive grammar, which focuses on the capacity of students to memorize lists of rules and exceptions to these rules, while it is often the case that neither the rule nor the exception to the rule can explain authentic examples in context. Students of English as a Foreign Language should understand how this language works to master it (Adamczewski, 1978). This article will show the adequacy of Metaoperational Grammar to this effect: In fact, the theoretical approach adopted in this analysis is context-based, communication-based, and researchbased. It is context-based because it considers that the only way to get insights into the internal organization of languages is to explore grammatical forms in context, that is, to examine them in their natural contexts of use, highlighting the importance of using authentic examples. It is communication-based because it gives prime importance to the elements of communication that are omnipresent in any communication process: encoder, decoder, the context of the situation, cotext, goal of communication, and strategies of communication, which depend on the relationship between the speaker and the addressee and the intention of communication (Chouit, 2014). And it is research-based because it is a theory of Linguistics, based on a holistic approach of how natural languages work, and the main principles that govern the processing of utterances in the communication process.

The main aim of this research article is to show how to invest grammatical mechanisms in making students achieve proficiency in English (Chouit \& Nfissi, 2018). Contrasting grammatical forms is one of the best approaches to this effect, provided that they are analyzed in context, using a solid theoretical approach. This article is devoted to the study of the dichotomies: present simple/present continuous and past simple/past continuous. To show the limitations of descriptive 
grammar, I will analyze the most common rules used by these approaches. Then, based on the theoretical framework of Metaoperational Grammar and the works of Henri Adamczewski on BE+ING $(1974,1978)$, I will present a rational and explanatory approach to the processing of these grammatical forms.

\section{Present simple and present continuous \\ Descriptive grammar}

Most grammars and reference books present a compilation of the various uses of each tense (Murphy, 1994; Brieger \& Sweeney, 1994; Werner \& Nelson, 1996). For the present simple, these are the most common uses referred to (1) to describe a permanent/general truth or current belief; (2) to express regular or habitual actions; (3) to talk about the general present; (4) it is often used in commentaries, especially when the action is quick; (5) in headlines and captions; (6) for giving instructions, directions, or demonstrations; (7) with a future time marker, it is used to indicate a fixed schedule in the future; (8) it is used with stative verbs.

As to the present continuous, here are the most common uses mentioned in most grammars: (1) to indicate activity at or around the time of speaking; (2) to indicate the temporary nature of an activity; (3) to indicate an action in progress at the moment of speaking, (4) to indicate a fixed arrangement in the future; (5) to indicate repeated annoying actions/regrettable habit; (6) when stative verbs occur in the progressive, they generally have different meanings.

\section{Analysis of descriptive approaches to grammar}

Preliminary remarks about these commonly-stated lists of realizations of the present simple and the present continuous forms reveal many weaknesses of the traditional approach to grammar. First, these listings target the capacity of students to memorize, not their capacity to understand and analyze. I think that this is rather an added burden to their learning load than a means to enhance their proficiency in English. Second, what predominates in these descriptions is what happens in the outside -extralinguistic- world, not what happens in the processing of utterances: the focus is on the action or activity taking place in the real world, not on the linguistic operations underlying utterances (Adamczewski, 1982). This means that such descriptive approaches are not abstract enough to be able to account for the abstract operations of utterance-building. But, we do not always talk to refer to actions; we also talk to reflect on actions. Third, in most cases, examples given to illustrate these uses are presented out of context, which deprives students of the opportunity to set a bridge between language and communication. This is why after having studied all these uses, they fail to link these grammatical forms to particular relevant contexts, and they have difficulty in gaining confidence in personal expression as these random lists of rules do not endow them with the capacity to select the appropriate grammatical form relevant to a particular communication context.

A simple question asking students to provide a suitable context for each of the following sentences constitutes a real challenge to them:

I leave tomorrow.

I am leaving tomorrow.

The explanation they could provide is that sentence (1) expresses the intention to leave the next day, while sentence (2) talks about arrangements already made to leave the following day. But, they can't provide a context for which only one of these forms would be acceptable. They need a rational explanatory approach to understand the difference between these grammatical forms. This is why they should be introduced to recent linguistic research that could bring insights into the emergence of grammatical forms in discourse. Metaoperational Grammar has proved its pertinence in this regard as this study will show. 


\section{A reappraisal of English grammar: Metaoperational grammar}

Metaoperational Grammar considers exploring grammar in context a condition to gain proficiency in a particular language and to get insights into the inner organization of languages. This theoretical framework revolves around the discovery that grammatical operators like the present simple and the present continuous forms are visible discursive traces of the invisible operations underlying the building of utterances, in the sense that when we communicate, we do not transmit messages only, but also the way they have been processed from mind to discourse. If these abstract operations underpinning the construction of utterances are invisible to the layman, it is the task of linguists to forge theoretical tools to make them intelligible (Adamczewski, 1982;2000;2002).

Metaoperational Grammar uses grammatical operators as natural meta-language to decipher what happens in the process of utterance construction. Note that the analysis targets the level of the abstract operations underpinning the processing of utterances. This is why the theoretical tools used to explain these processes should be able to account for the abstract nature of linguistic operations. This study will prove the importance of this approach to language, as we cannot understand how language works if we simply attach to language structures the various meanings relating to the real world such as notions based on actions and activities in the extralinguistic world: permanent activities, transitory actions, action in process at the time of speaking, etc.

Let us go back to the two examples of the dichotomy present simple/present continuous mentioned above to provide a specific context for each sentence of this pair and to explain them within the theoretical approach of Metaoperational Grammar.

Sentence (1), I leave tomorrow, may be said to announce the date of departure TOMORROW while sentence (2), I'm leaving tomorrow, is said in a completely different context: an apology for not being able to accept, for example, an invitation for dinner the next day because of a decision taken before the moment of speaking. The present simple is used to inform the interlocutor about the DATE OF DEPARTURE; therefore, the most important element in the utterance is TOMORROW. On the contrary, the present continuous is used to justify why the speaker cannot accept the invitation. The most important element in this utterance is the grammatical subject (I) (Adamczewski, 1978)..

This leads us to the key sub-theory of Metaoperational Grammar, which is the binary system of OPEN CHOICE versus CLOSED CHOICE, known as the Theory of Phases: Phase 1 versus Phase 2. In the chronology of the abstract processing of utterances, Phase 1 refers to the first stage of selection of elements from an open list of possibilities while Phase 2 builds on pre-existing information to justify it, explain it, or comment on it.

This binary system of OPEN/CLOSED CHOICE is best exemplified by the pair present simple/present continuous. With the present simple, the adverb of time is selected from an open list of possibilities; it could have been THIS EVENING, NEXT WEEK, ON SATURDAY, or any other day. This is why a possible reaction to this utterance could be: "You might just as well stay until the day after tomorrow and leave."

This kind of reaction is impossible for example (2), I am leaving tomorrow because the present continuous manifests the realization of the post-selection phase: Phase 2. As stated earlier, the present continuous is used to present an unarguable rejection of an invitation, based on an antecedent decision -the speaker has already bought his air ticket. Therefore, the addressee will not venture in negotiating the date of departure as he/she knows through decoding the BE+ING form that the subject is closed to debate (Adamczewski, 1978).

As it can be seen from this explanation, the abstract binary system of Open Choice versus Closed Choice is underlined by a difference in the orientation of utterances. With the present simple, the orientation of the utterance is towards what comes up in discourse with the focus being on the verb and/or its complements. On the contrary, with the present continuous, the orientation is towards what has preceded in discourse, preexisted in the context of a situation or shared knowledge, with the focus being on the grammatical subject. This explains why Metaoperational 
Grammar highlights the importance of the context and the importance of abstraction to be able to account for the abstract nature of language. The following sentence, when given out of context, will lead to a different interpretation than the one intended by the writer.

3. "You are crying now."

This example out of context may easily lead to the interpretation of "an action in process at the moment of speaking." However, it would be interesting to put it in its natural context and to contrast it with the present simple form.

3. 'Yes. But why do you always wake so early?'

'It is a business habit.'

'Oh, I wish you were not in that business, and that you were not going to die.'

'So do I', said the Colonel. 'But I'm getting out of the business.'

'Yes,' she said, sleepily and comfortably. 'Then we go to Rome and get the clothes.'

'And live happily ever after.'

'Please don't,' she said. 'Please, please, don't. You know I resolved not to cry.'

'You're crying now,' the Colonel said. 'What the hell have you got to lose on that resolution?' (E. Hemingway: Across the River and into the Trees, p.118)

4. "Former Pakistani PM Benazir Bhutto cries upon landing at Karachi International Airport Thursday." (See caption below: "Bhutto vows return of democracy," CNN.COM, October 18, 2007).

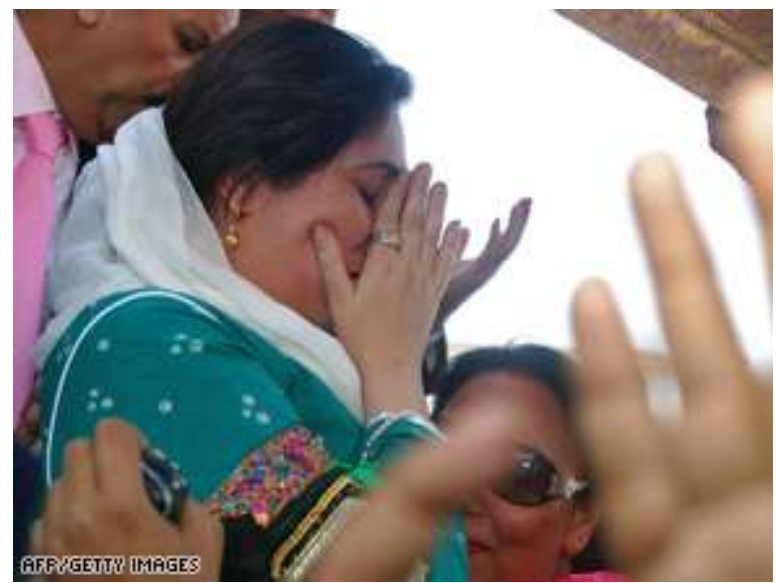

Figure 1. Former Pakistani PM Benazir Bhutto cries upon landing at Karachi International Airport Thursday.

The fundamental question here is the following: Which grammatical form refers to the action taking place at the moment of speaking "cries" or "are crying now"? The key to this question is to identify the focus in each of these two sentences. The focus in example (4) is on the verb CRIES representing the scene: Former Prime Minister of Pakistan cries upon landing at Karachi International Airport after eight years of self-imposed exile. The focus in example (3) is on the grammatical subject YOU, being commented on by the speaker, the Colonel, who used the BE+ING form to comment on the addressee's previous utterance: "I resolved not to cry". Despite that, she was crying, hence the comment of the Colonel: "[but] you're crying now [!]." It is clear in this context that the intended message was not simply to refer to an action in process at the moment of speaking, but to use this situation to comment on a previous utterance. What is of primary importance with the present continuous is not the act in itself but how the speaker reflects on that act. On the contrary, what is of primary importance with the present simple is the act itself as denoted by the 
verb. In fact, in these two examples, it is the one in the present simple which highlights the verb; and it is the verb that indicates action. Therefore, contrary to a well-established presumption, when we want to talk about actions taking place in the outside world, it is the present simple that is used, NOT the present continuous. This explanation is confirmed by the Colonel's emphasis on that resolution: "What the hell have you got to lose on that resolution?" The other occurrence of $\mathrm{BE}+\mathrm{ING}$ in this example confirms this analysis: "But I'm getting out of the business" is a clear comment on the wish previously stated by the addressee: "I wish you were not in that business." And it is completely unthinkable to relate it to an action taking place or in process at the moment of speaking.

These examples show the importance of contrasting grammatical forms. Only then can we challenge traditional descriptions of grammatical forms and prove their inadequacy. The two examples with the verb CRY in the present simple and the present continuous are particularly revealing in this regard. These examples show clearly the difference in orientation that underlines the difference between the present simple and the present continuous. The former is oriented towards what comes up in discourse, while the latter builds on what has already been stated in the previous context or existed in the situation of communication. This is why the focus in simple present sentences is on the verb and/or its complements, while the focus with the BE+ING form is on the grammatical subject. The BE+ING form is context-dependent in the sense that what it refers to should pre-exist to its emergence in discourse, either in the previous context or in the situation of communication. This is what enables the speaker to use this form to talk about the grammatical subject, to comment on a previous utterance or situation of communication. Therefore, the attitude of the speaker vi-à-vis the addressee is not the same as may be depicted from these grammatical operators in use: the present simple is meant for purely informative purposes because the interlocutor is not expected to know this piece of information, hence the orientation towards what comes up in discourse to get the intended message. On the other hand, the speaker uses the present continuous form for analytical purposes; the material to be commented on is shared by both parties in a communication act. This explanation is confirmed by the following examples:

5. "Ray Krone spent 10 years in an Arizona prison waiting to be executed for a murder he didn't commit. Now a campaigner against the death penalty, he describes the long fight to win back his freedom." (The Guardian Weekly, "Life after death row," November 23, 2007) 6. "The war in Afghanistan is being lost. It is best to acknowledge that. A survey coming out of Kabul conducted by the Senlis think-tank suggests that 54 percent of Afghanistan is now in the control of the Taliban. The Foreign Office may dispute the figure but it cannot quarrel with the substance of the findings." ("A policy overhaul is urgently needed", The Independent, 22 November 2007)

7. "The new curriculum for 11-14-year-olds, due to start in September, puts much greater emphasis on teacher innovation and local adaptability to pupils' needs." ("What makes a good teacher?" BBC NEWS, 26 January 2008)

8. "The very words "peace process" have a narcotic effect, and that's not all bad. They are the diplomatic equivalent of creating facts on the ground. They become the focus of attention. They distract from other problems. In the Middle East that is already far too volatile, this tranquilizing aspect of the Annapolis process is useful -- and shouldn't be squandered. ("How Annapolis Helps", The Washington Post, November 28, 2007, p. A23)

Examples (5) and (6) confirm the binary system underlying the processing of the present simple and the present continuous. On the one hand, the journalist in example (5) talks about a dossier that the audience does not know: the article aims to bring to their knowledge Ray Krone's 
"long fight to win back his freedom," hence the use of the present simple to emphasize the communicative value of the verb and its direct object: "describes the long fight to win back his freedom." On the other hand, the editorialist uses BE+ING in example (6) to refer to presupposed information concerning "the war in Afghanistan" that "is being lost", as evidenced by proofs given in the article. This is a conception of most importance to bear in mind while analyzing BE+ING forms, the comment is always based on solid proofs, hence its presupposition, i.e. its presentation as something closed to debate. On the contrary, the information forwarded through the present simple is presented from a multiple view perspective; that is to say, it is one possible vision within an open paradigm. This is particularly clear in examples (7) and (8) where the direct object plays a pivotal role, which explains recourse to the present simple tense. In example (8), the importance of the complementation A NARCOTIC EFFECT is shown in the fact that one full paragraph is devoted to explaining it to readers. No wonder then that the present simple is used throughout this paragraph.

This approach helps to explain some occurrences of BE+ING considered by most grammars as "idiomatic" as they pose a real problem to students:

\section{9. "This child is always knowing something she isn't supposed to!"}

(Adamczewski, 1982 : Grammaire linguistique de l'anglais, p.67)

10. "WIFE: Tell me everything you saw.

FENG: How can I? It's rather a long story. (...)

WIFE: What were you doing in Hankow?

FENG: Teaching.

WIFE: Really now, you should have stuck at it. What has

brought you scarping north instead?

FENG: I'm visiting the playgrounds of my childhood.

WIFE: That's just one of the reasons. What about the others?

FENG: Isn't one enough? There are many reasons; I can't identify them sometimes.

WIFE: You are being evasive.

(L. Jianwu: It's Only Spring, pp. 18-19)

These examples are not "exceptions" or "idiomatic" realizations of the present continuous, as they can easily be explained within the theoretical framework presented in this research article. In example (10), the use of the present continuous to comment on the attitude of the addressee vis-à-vis the various questions asked by the speaker is consolidated by the previous context which shows clearly that the interlocutor has been trying to avoid giving specific answers. And in example (9), the continuous form is triggered by shared knowledge about the grammatical subject SHE, who is known to be pocking her nose in matters, not of direct concern to her. This situation led the speaker to target her in his comment, knowing that the interlocutor shares with him the same view. This double orientation, either to the right towards the verb and its complements with the present simple, or to the left towards the grammatical subject with BE+ING is underlined by the abstract opposition between Open Choice versus Closed Choice as it has been explained above. The part played by grammatical operators in building semantic interpretation is to be highlighted in this regard. The present simple and the present continuous forms reflect two different communication strategies of the speaker, depending on the context, the situation of communication, the goal of communication, and the attitude of the speaker vis-à-vis what he structures and vis-à-vis the addressee. This explanation has also shown the important role they play is in encoding and decoding messages and building semantic interpretation. 
I would like to highlight the didactic outreach of a linguistic grammar of English, able to explain the processing of utterances in a simple, coherent, and logical way which reflects the internal organization of the English language. We indeed welcome with joy the increasing number of context-based grammars, but the context without appropriate theoretical tools would not be sufficient to account for grammatical operators in use as it can be seen from what follows.

\section{I0. Contrasting Metaoperational Grammar and other Context-based Approaches}

In Teaching Tenses, where the context is given particular attention, Aitken (1992) recommends that the present continuous with adverbs such as ALWAYS be "probably best taught as an idiom, at an intermediate or advanced level." The author gives the following clarifications:

It may be helpful to view the present continuous when used as a present tense as dealing with actions that began before the moment of speaking, are expected to continue past it, but are essentially transitory.

(...)

Regrettable habit with always (This is confusing as habit usually requires present simple.) I'm always losing my keys. This suggests that the speaker is constantly in a state of having lost the keys. (The action is repeated but transitory: compare - I always lose my keys.) (p.13)

Likewise, Carter et al. (2000) make the following comment:

\section{Present continuous for regular actions/events}

If the sentence contains an adverbial expressing habits or regular events, or if there is some other indication of repeated events, it does not necessarily mean that the present simple must be used. If the emphasis is on an ongoing process, or what is happening at a given, specific time, present continuous may be more appropriate:

Their numbers build up on the River Exe over autumn until by mid-winter some 6000 birds are regularly using the roost.

They're winning every other game. They're not drawing any games.

\section{Present continuous and physical states}

When we refer to physical feelings experienced at the time of speaking, we can often use the present continuous or present simple, without any major difference in meaning:

My back hurts. Or: My back's hurting.

Can I sit down? I feel a bit dizzy. Or: Can I sit down? I'm feeling a bit dizzy.

I do recognize that exploring grammar in context is a big step forward, yet it needs to be consolidated by theoretical tools able to account for the abstract operations underlying the processing of utterances. This is why I have highlighted the importance of a research-based grammar, which invests the findings of linguistic research in the analysis of grammatical forms, provided that the linguistic approach adopted is not a simple descriptive approach. Two main points are to be underlined in this regard. (1) Some aspects of grammar are still considered "idiomatic" in some approaches, while they are fully intelligible within the Metaoperational framework. (2) Contrary to what has been advocated in the last quotation, stating that "we can often use the present continuous or present simple, without any major difference in meaning," I do believe that there is no single occurrence in English usage where the present simple and the present continuous would have the same meaning. Otherwise, what would be the justification for the existence of two distinct forms? The examples cited in this quotation are easily explicable within the theoretical framework of the Metaoperational Grammar: "My back hurts" and "My back is hurting" would be used in completely different contexts, with substantial differences in meaning. The sentence with the present simple may be given as an answer to the following question: "What's the matter? Are you all 
right?" This question shows that the speaker does not know the problem, and waits for the answer to know what happens. Here the addressee has to use the present simple to provide this new piece of information. The sentence with BE+ING would be used in a totally different context, as an excuse, for example, not to carry heavy bags: "I can't help you, my back is hurting." This shows that the focus is different in these two sentences: with the present simple, the focus is on the verb "hurts", but with the present continuous, the focus is on the grammatical subject "I".

Therefore, even if analyzed in context, relying on traditional descriptive approaches does not bring new insights to the emergence of these grammatical forms in discourse. On the contrary, traditional inadequacies and inconsistencies persist. It is to be highlighted that we are faced with subtle meanings, difficult to detect because they are not clear overtly, but it is the task of linguists to make them clear. The trap to avoid, anyway, is to tailor the grammatical functioning of operators to the action taking place in the real world. Notions such as the incompleteness of the action and ongoing process at the time of speaking often used to describe the present continuous prove to be impertinent as to explaining grammar in use, as the following examples show:

11. "And now the Queen walks to the throne (heard during the Coronation of Elizabeth II)." (Adamczewski, 2002: The Secret Architecture of English Grammar, p.18)

12. "The water in the bowl gently ripples over in the breeze. Large ships push forward slowly, and the water foams about the extended oars that beat a fixed rhythm." (T. Vilhjalmsson: Quick Quick Said the Bird, p.19)

In these two examples, the context favors the interpretation of progressive action taking place at the time of speaking (c.f. NOW, GENTLY, SLOWLY), yet it is the present simple which is used, not the present continuous. Such examples show the serious limitations of descriptive grammar, and confirm the explanation within the Metaoperational framework provided in this research article. It is the present simple which is used to refer to actions taking place in the real world, including actions taking place at the time of speaking. The present continuous is used to comment on, explain, or justify pre-existent actions, situations or utterances. Here are other examples which are simply unexplainable within the traditional grammar framework:

13. "Obama keeps trying to connect Clinton's Iraq vote to her recent vote designating Iran's Revolutionary Guard Corps a terrorist group, suggesting that once again she is giving Bush the green light to launch a war."

("Obama's Amnesia Problem", The Washington Post, November 28, 2007; P.A23)

14. "- Who has disappeared?

- 'An au pair girl', said Poirot

- Oh well, said Mrs. Oliver, they're always disappearing, aren't they?"

(Adamczewski, 1982 : Grammaire linguistique de l'anglais, p.67)

15. "Look at this exchange (from the film Clueless) between a father and the young man who has come to take his daughter out:

FATHER: Do you drink?

YOUNG MAN: No, thanks, I'm cool.

FATHER: I'm not offering, I'm asking IF you drink. Do you think I'd offer alcohol to teenage drivers taking my daughter out?"

(Thornbury, 1999: How to Teach Grammar, p.6) 
These examples show how context-dependent is the BE+ING form; no one would say that in example (13), Hilary Clinton is actually "giving Bush the green light to launch a war." As we have already explained, the grammatical subject SHE is targeted by the speaker's comments, based on justifications mentioned in the previous context. Therefore, contrary to a well-established tradition making of the grammatical subject the agent of action at or around the time of speaking, in $\mathrm{BE}+\mathrm{ING}$ forms the grammatical subject is primarily the target of the speaker's comments and explanations based on proofs from the context or the situation of communication. Adamczewski states this clearly in the following quotation (2002):

In other words in all BE+ING sentences, the speaker is SAYING something about the grammatical subject. Now this contradicts what grammars have been telling us so far: the progressive form was considered as the DYNAMIC form par excellence, a form where the grammatical subject was DOING SOMETHING, was the agent of action with duration, etc. What one could say to excuse that blunder is that traditional grammars have always been mixing up grammatical facts and the actual events of the extra-linguistic world: the direct assignment of meaning to the markers of grammar has veiled the existence of the natural metalanguage and its role in the marking of the deep grammatical operations taking place during the processing of our utterances. Moreover, the linear approach has thwarted all attempts at a correct analysis of the facts of discourse.

This mechanism underlying the emergence of the BE+ING form is particularly clear in examples (14) and (15). In example (14) "they're always disappearing" is a clear comment on the disappearance of an au-pair girl stated in the previous context, while the comment in example (15) is based on the situation of communication and the reply of the young man which shows that there is a problem of miscommunication. The explanation provided so far shows that the inconsistencies of traditional grammar could not but have devastating effects on students' capacities to learn English, as they are confused when they are faced with examples such as the last ones (11-15). The irregularity of descriptive rules makes the task even harder. As languages are systematic, students should be equipped with appropriate theoretical tools to perceive that fundamental property in language organization, which is a prerequisite to attain fluency in English.

For Metaoperational Grammar, the abstract mechanisms accounting for the processing of the present simple and the present continuous can explain all the occurrences of simple forms as opposed to BE+ING forms, with no exceptions. This approach represents, in fact, a reappraisal of English grammar stemming from a coherent, rational, and explanatory theoretical approach. The explanation of the dichotomy present simple/present continuous is at work for the past simple and past continuous, the only difference being a connection to the present moment of speaking with present tenses and disconnection from the present moment of speaking with past tenses. The speaker uses the past simple to inform the addressee about events that took place in the past, while the past continuous is used to talk about the grammatical subject in the past, commenting on actions that happened in the past.

\section{Past Simple / Past Continuous}

16. "Opponents of cloning animals for food got a boost yesterday as a European ethics body came out against the practice, expressing concerns about the clones' welfare." ("European Ethics Group Opposes Food from Cloned Animals", The Washington Post, January 18, 2008; Page A16)

17. "Clinton followed up with her strange references to the Reverend Dr. Martin Luther King Jr. and President Lyndon Johnson - and no matter how many times she tried to reframe the quote, the feeling hung in the air that she was denigrating America's most revered black leader." ("Race and politics," International Herald Tribune, January 17, 2008) 
18. "'We know from experience that democracy is the only system of government that yields lasting peace and stability,' he [President Bush] added.

Yet he was speaking about democracy in a deeply undemocratic country." ("Bush: Iran threatens world security", CNN.COM, January 14, 2008)

19. "I remember that day clearly from start to finish. It was April 8, 2002, a Friday. It began as just another day in prison but at noon I was told my attorney was on the phone. He asked me how I was doing and I said: 'Oh you know, fine, just another day in paradise.' He laughed and said: 'What are you hungry for, Ray?' and I said that I guessed I'd eat whatever was in the chow hall. But he kept on and said: 'No really, you want steak, seafood? How about a Margarita?' I asked him what the devil he was talking about and that's when he said: 'I just got off the phone with the prosecutor's office. They're cutting the paperwork. You're going home today.'" ("Life after death row", The Guardian Weekly, November 23, 2007)

In example (16), the journalist used the past simple to report what happened the previous day consolidating the position of opponents of cloning animals. In this example, it is clear that the most important information is contained in the verbs and their complements: What did opponents of cloning animals get? A BOOST; when? YESTERDAY; how? A European ethics body came out against the practice. The informative nature of this piece of news is evident, hence the use of the past simple which orients the reader towards what comes up in discourse. The same explanation applies to occurrences of the past simple in examples (17) and (18). On the other hand, the orientation of the BE+ING form is towards what has been said in the previous context. In example (17), the position of the editorialist is clear in the use of the past continuous tense to comment on the references to Reverend Dr. Martin Luther King by the Presidential Candidate Hilary Clinton. Likewise, the comment of the journalist on the speech of President Bush is clear in example (18): highlighting the virtues of democracy in "a deeply undemocratic country"! The traditional explanation of the BE+ING form as referring to temporary action in the past or action in process in the past is completely irrelevant here. These examples show that the focus is not at all on actions in the past, but on how either actions or utterances in the past were reinvested by the speaker to transmit particular views, comments, or explanations, the target being the grammatical subject that receives the comment of the speaker. This is particularly clear in example (19) where the speaker, a prisoner sentenced to death, failed to understand the jokes of his lawyer; therefore, he asked him "what the devil he was talking about," showing his negative attitude towards what has been said and seeking clarification.

These examples confirm the serious limitations of descriptive grammar which constitute a real handicap for students to achieve proficiency in English. Here are other examples which cannot be explained within the traditional framework:

20. "Inch by inch he opened the door and entered the room!"

(Adamczewski, 1974: BE+ING Revisited, p.48)

21. "Then, inch by inch the intemperate heat crept into the heart of the Jungle." (Kipling: The Jungle Book, p.14)

22. "When they arrested me, they thought they were arresting a poor man. "Adamczewski, 1982: Grammaire linguistique de l'anglais, p.58)

In examples (20) and (21) the writer uses "inch by inch" which implies the duration of action for some time, traditionally associated with the use of the BE+ING form in the past. Yet, it is the past simple which is used, not the past continuous. The orientation towards the verb and its complementation is evident in these examples. Example (20) describes what the grammatical subject 
DID, actions taken from an open list of possibilities, and example (21) tells what "the intemperate heat" DID: the informative force of the verb and its adverbial (CREPT INTO THE JUNGLE) is highlighted. As to example (22), it shows that the past continuous is triggered by the same abstract mechanisms as the present continuous. Firstly, the pre-existence of the predicate to which -ING applies is made clear in the previous context. Secondly, the speaker used this predicate to COMMENT on the grammatical subject THEY; this communication strategy is made explicit by the segment "they thought". This explanation confirms the systematic nature of the English language. The past simple/past continuous pair functions on the same lines as the present simple/present continuous micro-system. More than that, this explanation can be extended to all micro-systems -BEING/+BE-ING.

As it has been made clear from the analysis presented in this article, language is not only a vehicle for the communication of messages but also a vehicle of the grammatical process behind the organization and building of discourse. It is the capacity to address this type of question that gives credibility to a linguistic theory of discourse and makes a difference between descriptive approaches and explanatory approaches. Undoubtedly, explanatory grammar is the one that provides analytical tools capable to account for abstract linguistic operations and discourse relations. Speaking about "action" in connection to BE+ING is ignoring this abstract level which constitutes the very foundation of language.

\section{Conclusion}

This study has shown the considerable role played by the linguistic approach in understanding how a language works. Deciphering the mechanisms underpinning the processing of utterances is not an easy task if one is not equipped with adequate theoretical tools. This is why this study has questioned the validity and accuracy of traditional grammar and descriptive approaches, which link grammatical forms directly to actions and events taking place in the extralinguistic world, instead of helping students understand what happens in the process of utterance construction and the criteria upon which the choice between the simple forms and the continuous forms is done in a particular context of communication. There is no doubt that the approach adopted in teaching grammar plays a fundamental role in students' achievements and learning capacities. This is why this study highlighted the limitations of descriptive approaches and their implications for students' abilities to attain fluency in English and to be effective communicators.

Metaoperational Grammar has proved pertinent in this regard. It has enabled me to show the importance of exploring grammar in context; the relevance of a linguistic grammar of English, targeting the organizing mechanisms of discourse; and the pedagogical outreach of such approach. One of the major points illustrated in this study is the part played by grammatical operators in building semantic interpretation. It has shown that the meaning of utterances is the outcome of a series of abstract operations and that grammatical operators like the simple form and the BE+ING form do participate in encoding and decoding messages, according to the context, the goal of communication, and the relationship between the speaker and the addressee. Based on authentic examples in context, this study has shown that the dichotomies present simple/present continuous and past simple/past continuous underlined by the abstract two-phase system OPEN CHOICE/CLOSED CHOICE, further explained by the difference in ORIENTATION between elements of these pairs. Simple verb forms are oriented towards what comes up in discourse: the verb and/or its complements while continuous forms are oriented towards the grammatical subject, being the target of the comments of the speaker. This double-orientation shows on the one hand the informative value of the verb and/or its complements in the simple forms, and on the other hand, the presupposition of the predicate to which -ING applies in the continuous forms.

The systematic nature of the English language is to be highlighted in this regard; the explanation presented in this study can be extended to all micro-systems -BE-ING/+BE-ING. This does not only help to make intelligible one of the most difficult chapters of English grammar but also gives insights into how the English language is organized. Such an approach, which does build 
better bridges for understanding grammar in use, would certainly help students gain proficiency and improve their communication skills in English.

\section{References}

Adamczewski, H. (1974). BE+ING Revisited. New insights in applied linguistics. Paris: Didier, pp.45-75.

Adamczewski, H. (1978). BE+ING dans la grammaire de l'anglais contemporain. Paris : Champion.

Adamczewski, H. (1982). Grammaire linguistique de l'anglais. Paris: A. Colin.

Adamczewski, H. (2000). The Architecture of English Grammar: from the Theory of Phases to the Principle of Cyclicity, paper presented at the Conference on Linguistics and the English Language, University of Toulouse-le Mirail, France, July 7-8, 2000.

Adamczewski, H. (2002). The secret architecture of english grammar. France: Editions EMA.

Aitken, R. (1992). Teaching tenses. Hong Kong: Thomas Nelson Ltd.

Brieger, N. \& Sweeney, S. (1994). The Language of Business English: Grammar and Functions. Great Britain: Prentice Hall International. Carter, R., Hughes, R., \& Mc Carthy, M. (2000). Exploring grammar in context. Cambridge: Cambridge University Press.

Chouit, D. (2014). A Linguistic Approach to Communication Strategies in Media Discourse. In D. Chouit (Ed.). Proceedings of the International Conference on Media, Culture and Education, Meknes 23-25 November 2010, Meknes: Meknes Print Shop, pp.25-38.

Chouit, D. \& Nfissi, A. (2018). Understanding Grammar in Context: A Step-by Step Guide. Fez: Info-Print.

Murphy, R. (1994). English Grammar in Use. (2nd ed.). Cambridge: Cambridge University Press.

Thornbury, S. (1999). How to teach grammar. Malaysia: Pearson Education Limited.

Werner, P.K. \& Nelson, J.P. (1996). A Content-Based Grammar. (3 ${ }^{\text {rd }}$ ed.). USA: McGraw-Hill. 